\title{
Pharmacological Profile of Naldemedine, a Peripherally Acting $\mu$-Opioid Receptor Antagonist: Comparison with Naloxone and Naloxegol[
}

\author{
Toshiyuki Kanemasa, Katsumi Koike, Kenji Takase, Tohko Arai, Atsushi Nakamura, \\ Yasuhide Morioka, and Minoru Hasegawa
}

Drug Discovery and Disease Research Laboratory (T.K., K.K., K.T., A.N., Y.M., M.H.) and Research Laboratory for Development (T.A.), Shionogi \& Co., Ltd., Toyonaka, Osaka, Japan

Received December 19, 2019; accepted March 10, 2020

\begin{abstract}
Opioid-induced constipation (OIC), a typical side effect of opioids, is due to activation of the $\mu$-opioid receptors in the enteric nervous system. Peripherally acting $\mu$-opioid receptor antagonists (PAMORAs) can reverse OIC by inhibiting the peripheral action of opioids without affecting centrally mediated analgesia. Naldemedine is a PAMORA with potent antagonist activity against $\mu-, \delta$-, and $\kappa$-opioid receptors. In this study, the pharmacological profiles of naldemedine, compared with those of naloxone and naloxegol, were evaluated. In vitro, Schild plot analysis indicated that naldemedine was a noncompetitive antagonist of $\mu$-opioid receptors, whereas other compounds were competitive antagonists. Also, naldemedine showed slower association and dissociation kinetics than the other compounds. In vivo, naldemedine dose-dependently ameliorated morphine-induced inhibition of small intestinal transit (SIT). The dose-response curve was not shifted at 1 and $3 \mathrm{mg} / \mathrm{kg}$ morphine. On the contrary, that of naloxegol was significantly shifted to the right from 1 to $3 \mathrm{mg} / \mathrm{kg}$ morphine. In morphine-dependent rats, naldemedine caused peripheral withdrawal symptoms (diarrhea) at doses higher than $1 \mathrm{mg} / \mathrm{kg}$, whereas the dose that produced
\end{abstract}

half the maximal preventive effect $\left(E D_{50}\right)$ against constipation was $0.03 \mathrm{mg} / \mathrm{kg}$. Naldemedine showed slower onset and a lesser severity of diarrhea than the other compounds at close to the $\mathrm{ED}_{50}$ value in the SIT model. Our results reveal that naldemedine has different pharmacological profiles (type of antagonism and binding kinetics) to the other compounds. This might explain the differential inhibition of morphine-induced SIT and withdrawal symptoms among the three antagonist compounds.

\section{SIGNIFICANCE STATEMENT}

Naldemedine is a novel peripherally acting $\mu$-opioid receptor antagonist with potent antagonist activity against $\mu-, \delta$-, and $\kappa$-opioid receptors. Naldemedine showed a noncompetitive antagonism and slower association and dissociation kinetics against $\mu$-opioid receptors than naloxone and naloxegol. Naldemedine showed insurmountable antagonism of morphine-induced inhibition and lower and slower peripheral withdrawal symptoms (diarrhea) than the other compounds. Therefore, naldemedine has a different pharmacological profile (the type of antagonism and binding kinetics) to the other compounds.

\section{Introduction}

Opioid analgesics are the standard therapeutic agents for the management of moderate to severe pain and alleviate pain predominantly by stimulating the $\mu$-opioid receptors in the central nervous system. However, their clinical use is limited by three major adverse effects (nausea/vomiting, constipation, and drowsiness) mediated primarily via $\mu$-opioid receptors (Swegle and Logemann, 2006; Benyamin et al., 2008). Opioid-induced constipation (OIC) is one of the most common and debilitating side effects of opioids and occurs primarily via activation of enteric $\mu$-opioid receptors, which results in a reduction in the frequency of small and large intestinal

All authors are employees of Shionogi \& Co., Ltd.

https://doi.org/10.1124/jpet.119.264515.

S This article has supplemental material available at jpet.aspetjournals.org. movement, development or worsening of straining, and hardstool formation after initiation of opioid therapy (Bell et al., 2009). OIC occurs in $40 \%-60 \%$ and $60 \%-90 \%$ of patients who take opioids for noncancer and cancer pain, respectively (Bruner et al., 2015).

The American Gastroenterological Association (AGA) has issued new guidelines on the medical management of OIC (Crockett et al., 2019). According to the guidelines, traditional laxatives are recommended as first-line agents to treat patients with OIC. If an adequate trial of laxatives results in suboptimal symptom control, the AGA recommends escalation of therapy to peripherally acting $\mu$-opioid receptor antagonists (PAMORAs). PAMORAs aim to reverse OIC by blocking opioid actions at peripheral $\mu$-opioid receptors in the gastrointestinal tract without adversely affecting analgesia. Currently three PAMORAs (naldemedine, naloxegol, and

ABBREVIATIONS: AGA, American Gastroenterological Association; brain Kp, brain-to-plasma concentration ratio; CRF1, corticotropin-releasing factor type-1; DAMGO, [D-Ala2, N-MePhe4, Gly-ol]-enkephalin; ED ${ }_{50}$, half maximal preventive effect; Kb, binding constant; Kd, dissociation constant; Ki, inhibition constant; Koff, dissociation rate constant; Kon, association rate constant; MME, morphine milligram equivalent; OIC, opioidinduced constipation; PAMORA, peripherally acting $\mu$-opioid receptor antagonist; SBM, spontaneous bowel movement; SIT, small intestinal transit. 
methylnaltrexone) are approved in the United States for OIC, and one (alvimopan) is approved for postoperative ileus. AGA strongly recommends naldemedine and naloxegol for OIC as second-line drugs because of high- and moderate-quality evidence of efficacy, respectively. Oxycodone/naloxone prolongedrelease tablets are also approved in the European Union to treat severe pain and were designed to address opioid-induced bowel dysfunction, including OIC, by combining the analgesic efficacy of oxycodone with selective blockade of enteric $\mu$-opioid receptors by naloxone (Morlion et al., 2018).

Naldemedine is a 7-carboxamide morphinan derivative of naltrexone (Inagaki et al., 2018): 17-(cyclopropylmethyl)6,7-didehydro-4,5 $\alpha$-epoxy-3,6,14-trihydroxy- $N$-[2-(3-phenyl1,2,4-oxadiazol-5-yl)propan-2-yl] morphinan-7-carboxamide 4-methylbenzenesulfonic acid. Naldemedine shows antagonist activity to $\mu-, \delta$-, and $\kappa$-opioid receptors (Kanemasa et al., 2019) and does not easily pass the blood-brain barrier (Watari et al., 2019). Naldemedine decreased OIC in several in vivo rat models at doses that did not compromise opioid analgesia. Naldemedine is indicated for the treatment of OIC as a oncedaily oral drug at a dose of $0.2 \mathrm{mg}$ in adult patients with chronic noncancer pain in United States, in patients with chronic noncancer pain and cancer in Japan, and in adult patients who have previously been treated with a laxative in the European Union. The effectiveness of naldemedine was established in seven phase III randomized, double-blind, and placebo-controlled trials of $0.2 \mathrm{mg}$ once-daily treatment of patients with noncancer pain or cancer pain (Hale et al., 2017; Katakami et al., 2017; Saito et al., 2018; Webster et al., 2018).

We evaluated the in vitro and in vivo pharmacological profiles of naldemedine compared with those of naloxone, a central-acting opioid antagonist, and naloxegol, another PAMORA. Briefly, the objective was to assess: 1) the binding and antagonist activities to $\mu-, \delta$-, and $\kappa$-opioid receptors and the types of antagonism to $\mu$-opioid receptors, 2 ) the binding kinetics to $\mu$-opioid receptors, 3 ) the effects on morphineinduced SIT inhibition caused by different morphine doses, and 4) the potential of withdrawal symptoms in morphinedependent rats. The results reveal that naldemedine had different antagonism and binding kinetics from the other compounds studied. This might explain the differential inhibition of morphine-induced SIT and withdrawal symptoms among the three $\mu$-opioid receptor antagonists.

\section{Materials and Methods}

Chemicals and Reagents. Naldemedine tosylate, naloxegol, $\left[{ }^{3} \mathrm{H}\right]$-naldemedine, $\left[{ }^{3} \mathrm{H}\right]$-naloxegol, morphine hydrochloride, and oxycodone hydrochloride were manufactured by Shionogi Research Laboratories (Osaka, Japan). Naloxone hydrochloride and U50,488H were obtained from Tocris Bioscience (Bristol, UK). Hydrocodone bitartrate and fentanyl citrate were purchased from Mallinckrodt Inc. (Hobart, NY). Saline and distilled water were obtained from Otsuka Pharmaceutical Factory, Inc. (Tokushima, Japan). For in vitro studies, the radioligands $\left[{ }^{3} \mathrm{H}\right]-\left[\mathrm{D}-\mathrm{Ala}^{2}, \mathrm{~N}-\mathrm{MePhe}^{4}\right.$, Gly-ol]-enkephalin (DAMGO; for $\mu$-opioid receptors), $\left[{ }^{3} \mathrm{H}\right]-\left[\mathrm{D}-\mathrm{Ala}^{2}, \mathrm{D}-\mathrm{Leu}^{5}\right]$-enkephalin (for $\delta$-opioid receptors), [ $\left.{ }^{3} \mathrm{H}\right]-\mathrm{U}-69,593$ (for $\kappa$-opioid receptors), $\left[{ }^{3} \mathrm{H}\right]$ naloxone, $\left[{ }^{35} \mathrm{~S}\right]-\mathrm{GTP} \gamma \mathrm{S}$, and recombinant human $\mu$-, $\delta$-, and $\kappa$-opioid receptors were purchased from PerkinElmer Life and Analytical Sciences, Inc. (Kanagawa, Japan). Evans blue dye, the vehicle for Evans blue dye (carboxymethyl cellulose sodium salt), and the vehicle for naldemedine (methylcellulose; $400 \mathrm{cP}, 0.5 \%$ solution) were obtained from Wako Pure Chemical Industries, Ltd. (Osaka, Japan).
Animals. Crlj: WI (Wistar) male rats were obtained from Charles River Laboratories Japan, Inc. (Kanagawa, Japan). Jcl: Wistar rats were purchased from CLEA Japan, Inc. (Tokyo, Japan). Hartley guinea pigs were obtained from Japan SLC, Inc. (Shizuoka, Japan). The animals were maintained under a 12-hour light/dark cycle and had ad libitum access to food and water. Rats were fasted for at least 20 hours for the SIT study or 15-24 hours for the antinociceptive model to render the stomach, small intestine, and colon empty prior to the experiment and received tap water ad libitum.

All studies were conducted at Shionogi \& Co., Ltd., except for the functional assays using guinea pig ileum, which were conducted at the Shiga Laboratory of Nissei Bilis Co., Ltd. (Osaka, Japan). The studies were conducted in accordance with the standards of the Institutional Animal Care and Use Committee, Institutional Animal Ethics Committee, and Shionogi's Institutional Animal Care and Use Committee.

Binding and Functional Assays for Human $\mu$-, $\delta$-, and א-Opioid Receptors. The in vitro binding affinities and antagonist activities of three $\mu$-opioid receptor antagonists for recombinant human $\mu$-, $\delta$-, and $\kappa$-opioid receptors were determined as described previously (Suzuki et al., 2018).

In binding assays, the inhibition constant (Ki) value for each sample was calculated using the following equation, and the concentration that inhibited $50 \%$ of specific binding $\left(\mathrm{IC}_{50}\right)$ was obtained: $\mathrm{Ki}=\mathrm{IC}_{50} \div$ $(1+[\mathrm{L}] \div \mathrm{Kd})$, in which $\mathrm{IC}_{50}$ is the concentration that inhibited $50 \%$ of specific binding, $[\mathrm{L}]$ is the concentration of the radioactive ligand used and $\mathrm{Kd}$ is the dissociation constant $(\mathrm{Kd})$ of the radioactive ligand. The Kd values of $\left[{ }^{3} \mathrm{H}\right]$-DAMGO for $\mu$-opioid receptor, $\left[{ }^{3} \mathrm{H}\right]-\left[\mathrm{D}-\mathrm{Ala}^{2}\right.$, D-Leu ${ }^{5}$-enkephalin for $\delta$-opioid receptor, and $\left[{ }^{3} \mathrm{H}\right]-\mathrm{U}-69,593$ for $\kappa$-opioid receptor were $0.52,0.69$, and $1.67 \mathrm{nM}$, respectively.

In functional antagonist $\left[{ }^{35} \mathrm{~S}\right]-\mathrm{GTP} \gamma \mathrm{S}$-binding assays, the binding constant $(\mathrm{Kb})$ value for the cellular assay was calculated as: $\mathrm{Kb}=\mathrm{IC}_{50} \div\left\{\left([\mathrm{A}] \div \mathrm{EC}_{50}\right)+1\right\}$, in which $\mathrm{IC}_{50}$ is the concentration of the antagonist producing $50 \%$ inhibition in the presence of agonist and $[\mathrm{A}]$ is the concentration that produces $95 \%$ stimulation of $\left.{ }^{35} \mathrm{~S}\right]-\mathrm{GTP} \gamma \mathrm{S}$ binding of the control agonist. The $\mathrm{EC}_{50}$ values of DAMGO for $\mu$-opioid receptor, [Met ${ }^{5}$ ]-enkephalin for $\delta$-opioid receptor, and $\mathrm{U}-50,488 \mathrm{H}$ for $\kappa$-opioid receptor are 54.71, 2.96, and $7.73 \mathrm{nM}$, respectively.

Data are presented as mean \pm S.E. in three independent experiments.

In Vitro Functional Assays of $\mu$-Opioid Receptor Using Guinea Pig Ileum. The ileum was prepared from guinea pig and suspended with an approximately 1-g load in an organ bath. The contractile responses were evoked by square-wave stimulation via a ring platinum electrode. After confirmation of a stable contractile response, the antagonist was added for 20 minutes, and DAMGO was cumulatively added to examine the effects on the contractile responses. The antagonist, at one concentration at a time, was administered to one ileum preparation, and three animals were used for the ileum preparations.

The $\mathrm{IC}_{50}$ value in the presence and absence of antagonist was obtained by calculating the linear regression line based on the leastsquares method using SAS and its cooperative system, EXAS ver. 6.10 (Arm Systex Co., Ltd). The concentration ratio (CR) was calculated using the following equation: $\mathrm{CR}=\mathrm{IC}_{50}$ in the presence of test compound $\div \mathrm{IC}_{50}$ in the absence of test compound

For each antagonist, the $\mathrm{p} A_{2}$ values were obtained from a Schild plot of the CR values. In the case that the slope of the line obtained by Schild plot was $\leq 0.8$ or $\geq 1.2$, the $\mathrm{p} A_{2}$ value was not determined. Data were expressed as mean \pm S.E. of three independent preparations.

Type of Antagonism to Human $\mu$-Opioid Receptor. The type of antagonism of the three antagonists against clinically used opioids was evaluated by $\left[{ }^{35} \mathrm{~S}\right]-\mathrm{GTP} \gamma \mathrm{S}-$-binding assay. Morphine-, oxycodone-, hydrocodone-, or fentanyl-induced $\left[{ }^{35} \mathrm{~S}\right]-\mathrm{GTP} \gamma \mathrm{S}$ binding was determined in the absence and presence of three antagonists (for naloxegol, hydrocodone and fentanyl were not used). To identify the antagonism, 
the slope of the Schild regression and its 95\% confidence interval were calculated.

Binding Kinetics Assays for Human $\boldsymbol{\mu}$-Opioid Receptor. Radioligandbinding assays for human $\mu$-opioid receptor were performed, and the Kd values of $\left[{ }^{3} \mathrm{H}\right]$-naldemedine, $\left[{ }^{3} \mathrm{H}\right]$-naloxone, and $\left[{ }^{3} \mathrm{H}\right]$-naloxegol were calculated using the Scatchard equation. Kd values were expressed as mean \pm S.E. of three independent experiments.

The association kinetics analysis involved the addition of radioligand at various time points and measurement of specific binding. The dissociation kinetics analysis was accomplished by allowing the radioligand and homogenate to bind to equilibrium, at which point further binding was blocked by the addition of $10 \mu \mathrm{M}$ (final concentration) unlabeled agonist at various time points and measurement of specific binding.

The observed association rate constant (Kobs) was determined from nonlinear regression fits of the data to a one-phase exponential association model: $\mathrm{B}=$ Beq. $\left(1-\mathrm{e}^{\left(-\mathrm{Kobs}^{*} \mathrm{t}\right)}\right)$, in which Beq is the specific binding (scintillation count) of radiolabeled ligand to the receptors at equilibrium, and $\mathrm{B}$ is the specific binding of radiolabeled ligand at a given incubation time $t$. The dissociation rate constant (Koff) was calculated from nonlinear regression fits of the data to a one-phase exponential decay model using the following formula: $\operatorname{Koff}=0.693 \div \mathrm{t}_{1 / 2}$, in which $t_{1 / 2}$ is the time until the binding of radiolabeled ligand to the receptor decreases to $50 \%$ after the addition of excess unlabeled ligand. The association rate constant (Kon) was calculated using the following formula: $\mathrm{Kon}=\mathrm{Koff} \div \mathrm{Kd}$.

Small Intestinal Transit Test. The antagonistic effect of the three antagonists on constipation caused by morphine-induced inhibition of SIT was determined as described previously (Suzuki et al., 2018). Briefly, 6-week-old Crlj: WI male rats were allocated into groups (10-12 per group) based on body weight and administered naldemedine (orally), naloxone (subcutaneously), naloxegol (orally), or vehicle, followed by morphine (15 minutes later; 1 or $3 \mathrm{mg} / \mathrm{kg}$ subcutaneously). Evans blue dye was administered intragastrically ( $0.5 \%$ in $2 \mathrm{ml}) 45$ minutes postdose. Rats were euthanized 15 minutes later by cervical dislocation, and the stomach and small intestine were quickly removed; the mesentery was completely separated to avoid circling. The distance traveled by the Evans blue dye relative to the total length of the small intestine was measured. Small intestinal transition was calculated as: small intestine transition $(\%)=($ distance moved by Evans blue dye $[\mathrm{cm}] \div$ total length of small intestine $[\mathrm{cm}]) \times 100$. The effect of the three antagonists or vehicle on morphine-induced inhibition of SIT was assumed to be the percentage maximal possible effect (MPE). The percentage MPEij for the jth individual in Group i maybe be found with $(\% \mathrm{MPEij})=([\mathrm{Yij}-\overline{\mathrm{Y}} 2] \div[\overline{\mathrm{Y}} 1-\overline{\mathrm{Y}} 2]) \times 100$, in which Yij is the small intestine transition for the jth individual in Group i, $\bar{Y} 1$ is the average small intestine transition in the vehicle control group (Group 1), and $\bar{Y} 2$ is the average small intestine transition in the morphine control group (Group 2). Dunnett's test for the anticonstipation effect was conducted among the morphine control group and antagonist groups. The $\mathrm{ED}_{50}$ values of each antagonist were estimated using a sigmoid Emax model.

Morphine-Withdrawal Model. The effects of the three compounds on withdrawal symptoms in morphine-dependent rats were evaluated as described previously (Kanemasa et al., 2019).
After 5 days of continuous morphine injection subcutaneously in rats using an osmotic pump, naldemedine (orally), naloxone (subcutaneously), and naloxegol (orally) were administered. Withdrawal signs were observed immediately and 1, 2, 4, 6, and/or 8 hours after dosing. Central withdrawal signs (jumping, wet-dog shakes, and teeth chattering) and peripheral withdrawal signs (diarrhea) were recorded. The number of times a rat jumped or had wet-dog shakes was counted for 20 minutes during each observation period. Diarrhea and teeth chattering were scored as follows: $0=$ normal, $1=$ slight to moderate, and $2=$ marked. All data at each time point were compared between the vehicle control and each dose of naldemedine by Steel's multiple comparison test. All data of naloxone and naloxegol at each time point were compared with the vehicle control by Wilcoxon rank-sum test. Statistical significance was set at the $P<0.05$ level. Statistical analysis was performed using SAS software (version 9.1; SAS Institute, Japan) for Microsoft Windows. Statistical significance was set at $P<0.05$.

\section{Results}

Binding Affinities and Antagonist Activities Against Human $\mu$-Opioid Receptor. The binding affinities and antagonist activities of naldemedine, naloxone, and naloxegol against recombinant human $\mu-, \delta$-, and $\kappa$-opioid receptors are shown in Table 1. Naloxone and naloxegol showed $\mu$-opioid receptor-selective binding affinities and antagonist activities. However, naldemedine showed high affinity and potent antagonist activity for human $\mu$-, $\delta$-, and $\kappa$-opioid receptors. The binding affinities and antagonist activities for human $\mu$-opioid receptor were similar among the three compounds.

Type of Antagonism of $\boldsymbol{\mu}$-Opioid Receptors. For competitive assays, the antagonistic activities of the three compounds were examined using isolated guinea pig ileum. The antagonism of the compounds against DAMGO-induced attenuation of electrical field stimulation-evoked contractions was evaluated using the slope of a Schild regression. The slopes of the Schild regression for naldemedine, naloxone, and naloxegol antagonism were $1.42,0.88$, and 0.93 , respectively (Fig. 1) The $\mathrm{p} A_{2}$ values of naloxone and naloxegol were 8.89 and 8.34, respectively. The $\mathrm{p} A_{2}$ value of naldemedine was not calculated because the slope of the Schild regression was $>1.2$. Furthermore, the antagonistic activities of the three compounds against commonly prescribed $\mu$-opioid receptor agonists were examined. Naldemedine and naloxone concentrationdependently blocked $\left[{ }^{35} \mathrm{~S}\right]-\mathrm{GTP} \gamma \mathrm{S}$ binding induced by morphine, oxycodone, hydrocodone, and fentanyl. Naloxegol also concentration-dependently blocked [35S]-GTP $\gamma \mathrm{S}$ binding by morphine and oxycodone. The slopes of the Schild regression for naldemedine, naloxone, and naloxegol antagonism are shown in Table 2. The 95\% confidence intervals of the slope of Schild regression for naloxone and naloxegol against all opioid agonists contained unity. However, those for naldemedine against all opioid agonists did not contain unity. Therefore,

TABLE 1

Specific binding and functional activities in relation to human opioid receptors

Values are mean \pm S.E. Mean of three independent experiments carried out in duplicate. Binding and functional activities of naldemedine were from Kanemasa et al. (2019).

\begin{tabular}{|c|c|c|c|c|c|c|}
\hline & \multicolumn{3}{|c|}{ Binding (Ki nM) } & \multicolumn{3}{|c|}{ Antagonist (Kb nM) } \\
\hline & $\mu$ & $\delta$ & $\kappa$ & $\mu$ & $\delta$ & $\kappa$ \\
\hline Naldemedine & $0.34 \pm 0.03$ & $0.43 \pm 0.08$ & $0.79 \pm 0.08$ & $0.50 \pm 0.05$ & $0.27 \pm 0.03$ & $0.32 \pm 0.03$ \\
\hline Naloxone & $0.43 \pm 0.70$ & $52.09 \pm 4.13$ & $2.63 \pm 0.66$ & $0.55 \pm 0.06$ & $24.74 \pm 1.74$ & $18.43 \pm 9.73$ \\
\hline Naloxegol & $0.49 \pm 0.10$ & $62.12 \pm 26.63$ & $40.78 \pm 2.14$ & $0.38 \pm 0.08$ & $6.26 \pm 0.89$ & $38.51 \pm 10.92$ \\
\hline
\end{tabular}



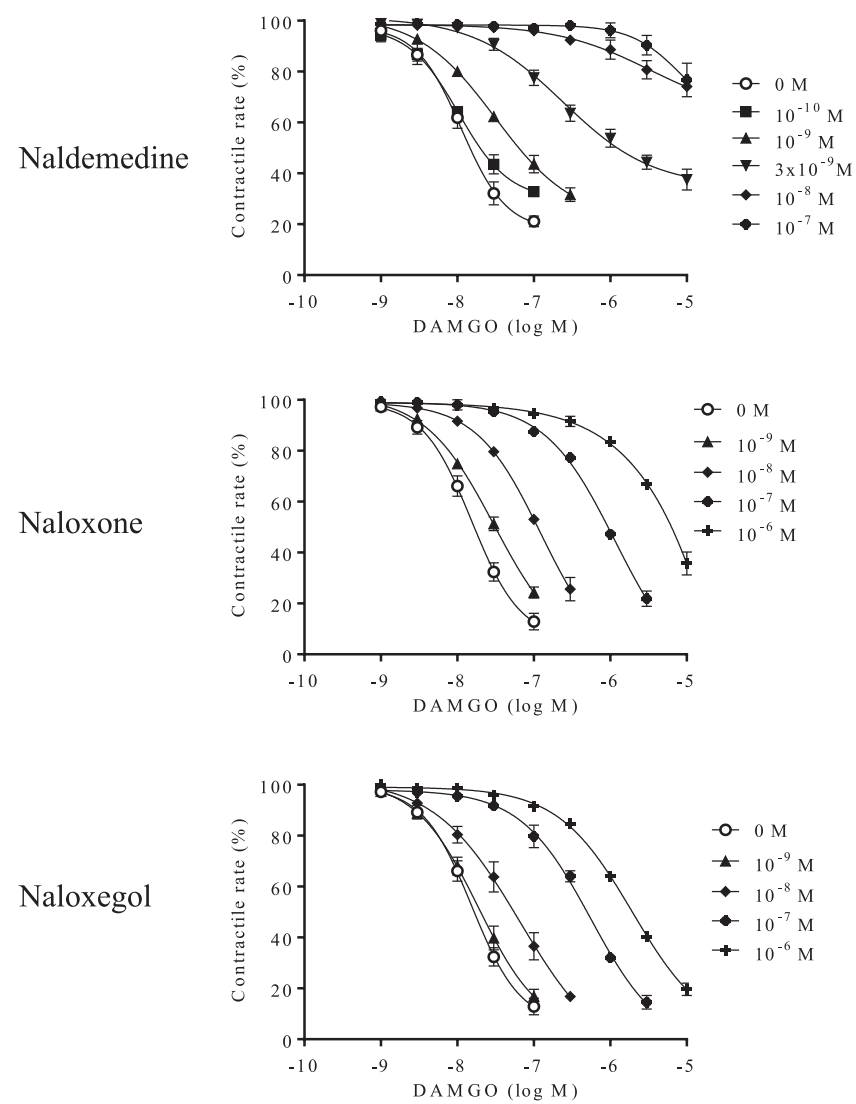

Fig. 1. Schild analysis of antagonism by DAMGO of $\mu$-opioid receptors in the guinea pig ileum. Effects of the indicated concentrations of naldemedine, naloxone, and naloxegol on the DAMGO concentration response curve. Means of three independent experiments are shown.

naldemedine, but not naloxone and naloxegol, possessed noncompetitive antagonist activity against $\mu$-opioid receptor versus several commonly prescribed opioids.

Binding Kinetics to Human $\boldsymbol{\mu}$-Opioid Receptor. It has been reported that many noncompetitive antagonisms of small-molecule G-protein-coupled receptors are associated with slow dissociation of antagonist from the receptor (Swinney DC, 2004). To evaluate the binding kinetics profile of naldemedine for $\mu$-opioid receptors, association and dissociation studies were performed. Radioligand-binding assays of $\left[{ }^{3} \mathrm{H}\right]$ naldemedine, $\left[{ }^{3} \mathrm{H}\right]$-naloxone, and $\left[{ }^{3} \mathrm{H}\right]$-naloxegol for human $\mu$-opioid receptor were performed; $\mathrm{Kd}$ values are shown in Fig. 2. From those results, $\left[{ }^{3} \mathrm{H}\right]$-naldemedine, $\left[{ }^{3} \mathrm{H}\right]$-naloxone, and $\left[{ }^{3} \mathrm{H}\right]$-naloxegol were used in the association and dissociation studies at $0.5,0.5$, and $7.0 \mathrm{nM}$, respectively. Naldemedine showed slower association and dissociation rates for binding to human $\mu$-opioid receptor than naloxone and naloxegol (Fig. 2). Also, the Kon and Koff values of naldemedine were lower than those of naloxone. The Kon value of naldemedine was similar to that of naloxegol; however, the Koff value of naldemedine was lower than that of naloxegol (Table 3). These results suggest that naldemedine has slow association and dissociation binding kinetics, which are likely to be due to noncompetitive antagonism of the $\mu$-opioid receptor.

Effects on Morphine-Induced Small Intestinal Transit Inhibition. Because insurmountable antagonism is associated with slow dissociation of the antagonist from the receptor (Swinney DC, 2004), the effects of the three compounds on morphine-induced SIT inhibition at high and low doses were evaluated. The three compounds showed dose-dependent suppression of subcutaneously administered 1 and $3 \mathrm{mg} / \mathrm{kg}$ morphine-induced inhibition of rat SIT, with $\mathrm{ED}_{50}$ values (95\% confidence interval) of $0.027(0.017,0.037) \mathrm{mg} / \mathrm{kg}$ and $0.034(0.012,0.055) \mathrm{mg} / \mathrm{kg}$ for naldemedine, $0.052(0.012$, $0.092) \mathrm{mg} / \mathrm{kg}$ and $0.124(0.074,0.174) \mathrm{mg} / \mathrm{kg}$ for naloxone, and $1.240(-0.103,2.582) \mathrm{mg} / \mathrm{kg}$ and $3.786(0.613,6.958) \mathrm{mg} / \mathrm{kg}$ for naloxegol, respectively (Fig. 3). Naldemedine showed a 1.26 -fold shift in the $\mathrm{ED}_{50}$ value from 1 to $3 \mathrm{mg} / \mathrm{kg}$ morphine, and the shift in the dose-response curve of the two doses was not significant $(P=0.267)$. In contrast to naldemedine, naloxone and naloxegol showed 2.38- and 3.05-fold shifts, respectively, in the $\mathrm{ED}_{50}$ value from 1 to $3 \mathrm{mg} / \mathrm{kg}$ morphine. Naloxegol, but not naloxone, showed a significant shift in the dose-response curves at the two morphine doses $(P=0.19$ for naloxone and $P=0.015$ for naloxegol). Therefore, naldemedine showed insurmountable antagonism of morphine-induced inhibition of SIT.

Withdrawal Symptoms in Morphine-Dependent Rats. Naldemedine at $>1 \mathrm{mg} / \mathrm{kg}$ caused a peripherally mediated withdrawal symptom (diarrhea) 1 or 2 hours after dosing and a significant centrally mediated withdrawal symptom at $3 \mathrm{mg} / \mathrm{kg} 1$ and 4 hours after dosing in morphinedependent rats (Supplemental Table 1A). The dose levels of naldemedine that did not cause peripherally or centrally mediated withdrawal symptoms were 0.3 and $1 \mathrm{mg} / \mathrm{kg}$, respectively. These dose levels were about 10 - or 30 -fold, respectively, the $\mathrm{ED}_{50}$ value $(0.03 \mathrm{mg} / \mathrm{kg})$ for anticonstipation activity ( $3 \mathrm{mg} / \mathrm{kg}$ morphine-induced SIT inhibition). Naloxegol and naloxone caused both peripherally and centrally mediated withdrawal symptoms at the doses close to $\mathrm{ED}_{50}$ values $(0.1$ and $3 \mathrm{mg} / \mathrm{kg}$ ) for anticonstipation activity (3 mg/kg morphine-induced SIT inhibition, Fig. 4; Supplemental Table $1 \mathrm{~B}$ and $1 \mathrm{C}$ ). Naldemedine at $0.03 \mathrm{mg} / \mathrm{kg}$ caused weak diarrhea (without statistical significance: $P=$ 0.82 and 0.82 ) at 2 and 4 hours after administration, whereas naloxegol $3 \mathrm{mg} / \mathrm{kg}$ and naloxone $0.1 \mathrm{mg} / \mathrm{kg}$ caused significant diarrhea immediately and 1 hour after dosing in morphinedependent rats, respectively. Therefore, naldemedine showed a slower onset of peripheral withdrawal symptom compared with naloxone and naloxegol (Fig. 4A).

TABLE 2

Schild analysis of antagonism by morphine, oxycodone, hydrocodone, and fentanyl of human $\mu$-opioid receptor by $\left[{ }^{35} \mathrm{~S}\right]-$ GTP $\gamma$ S-binding assay

Values of Schild slope are means and 95\% confidence intervals. Mean of three independent experiments carried out in duplicate.

\begin{tabular}{lcccc}
\hline & Morphine & Oxycodone & Hydrocodone & Fentanyl \\
\hline Naldemedine & $1.37(1.32-1.42)$ & $1.29(1.25-1.34)$ & $1.43(1.35-1.51)$ & $1.37(1.28-1.47)$ \\
Naloxone & $1.00(0.89-1.11)$ & $0.97(0.92-1.02)$ & $1.04(0.98-1.09)$ & $1.00(0.90-1.09)$ \\
Naloxegol & $0.98(0.94-1.02)$ & $1.00(0.94-1.06)$ & & \\
\hline
\end{tabular}




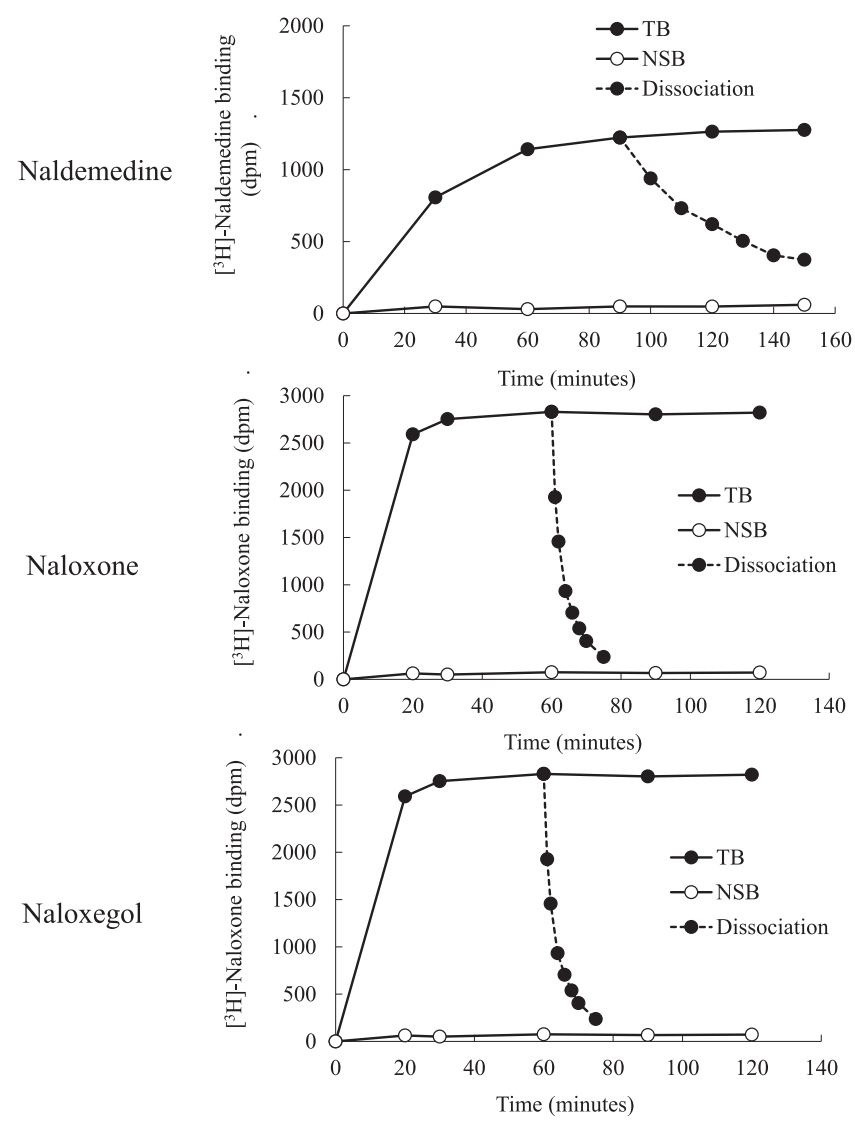

Fig. 2. Association (solid line) and dissociation (dashed line) binding kinetics of $\left[{ }^{3} \mathrm{H}\right]$-naldemedine, $\left[{ }^{3} \mathrm{H}\right]$-naloxone, and $\left[{ }^{3} \mathrm{H}\right]$-naloxegol to human $\mu$-opioid receptor. Binding of labeled compound in the absence (closed circle, total binding) or presence (open circle, nonspecific binding) of $1 \mathrm{mM}$ unlabeled compounds. The graphs represent one experiment, and similar results were obtained in two other experiments for each compound. NSB, nonspecific binding; TB, total binding.

\section{Discussion}

We investigated the pharmacological profiles of naldemedine compared with those of naloxone and naloxegol. All three compounds are $\mu$-opioid receptor antagonists; however, each possessed distinct antagonist type and binding kinetics. Naldemedine showed noncompetitive antagonism and slower binding kinetics, whereas naloxone and naloxegol showed competitive antagonism and faster binding kinetics under controlled conditions. This unique profile of naldemedine may explain its differential in vivo pharmacological effects versus naloxone and naloxegol. Naldemedine reversed the inhibition of SIT independently of the morphine dose. Also, in morphinedependent rats, the peripheral withdrawal symptoms of naldemedine were milder and of slower onset than those of naloxone and naloxegol. Thus, naldemedine, naloxone, and naloxegol exhibited unique antagonist/binding profiles, resulting in different in vivo pharmacological effects, under controlled conditions.

In in vitro functional assays using isolated ileum preparations in guinea pig (Fig. 1), the three antagonists produced concentration-dependent rightward shifts in the agonist (DAMGO) concentration response curve relative to vehicle. The rightward shifts of naloxone and naloxegol were parallel, but higher concentrations of naldemedine caused flattening of the dose-response curve. The slopes of the Schild regression for naloxone and naloxegol antagonism ( 0.88 and 0.93 , respectively) were closer to unity than that for naldemedine (1.4). These results show that naloxone and naloxegol are competitive antagonists, whereas naldemedine is a noncompetitive antagonist, because the slopes of the Schild regression of competitive antagonists are from 0.8 to 1.2 (Janković et al., 1999). In vitro functional assays confirmed that naloxone and naloxegol are competitive antagonists, whereas naldemedine is a noncompetitive antagonist. To clarify the difference among the types of antagonism in vivo, the effects of the three antagonists on morphine-induced SIT inhibition caused by two doses of morphine were assessed. Although the three compounds showed dose-dependent suppression of subcutaneously administered morphine-induced inhibition of rat SIT at 1 and $3 \mathrm{mg} / \mathrm{kg}$ morphine (Fig. 3), naldemedine showed a 1.26fold shift in the $\mathrm{ED}_{50}$ value at 1 and $3 \mathrm{mg} / \mathrm{kg}$ morphine; the shift in the dose-response curves at 1 and $3 \mathrm{mg} / \mathrm{kg}$ morphine was not significant. In contrast, naloxone and naloxegol showed a 2.38-fold and 3.05-fold shift in the $\mathrm{ED}_{50}$ value at 1 and $3 \mathrm{mg} / \mathrm{kg}$ morphine. The shift for naldemedine and naloxone was not significant, whereas that for naloxegol was significant. In clinical practice, there is wide variation in the doses of opioids prescribed to patients. For instance, the total daily dose of opioid in a phase 3 trial of naldemedine (Hale et al., 2017) ranged from less than $30 \mathrm{mg}$ to more than $400 \mathrm{mg}$ oral morphine equivalent. To avoid dose adjustment in patients prescribed opioids, the noncompetitive antagonism of naldemedine is preferable. The differences in the proportion of spontaneous bowel movement (SBM) responders between naldemedine and placebo groups were similar across baseline opioid dose strata in a phase 3 trial (Hale et al., 2017). An efficacy analysis based on opioid dose groups in a phase 3 trial showed that the proportion of SBM responders was higher in the naldemedine group relative to the placebo group for all opioid dose strata (Hale and Ko, 2019). The percentage increases in responders for the naldemedine groups compared with the placebo groups in the pooled population were as follows: 30 to $\leq 100$ morphine milligram equivalent (MME), $14.7 \%$; $>100$ to $\leq 200 \mathrm{MME}, 14.9 \%$; $>200$ to $\leq 400 \mathrm{MME}$,

TABLE 3

Binding kinetics to human $\mu$-opioid receptor

Values of Kd are means and 95\% confidence interval, and values of Koff and $\mathrm{T}_{1 / 2}$ are means of three independent experiments. Kon was calculated using following formula: Kon $=$ Koff $\div$ Kd.

\begin{tabular}{lcccc}
\hline & $\mathrm{Kd}$ & Koff & $\mathrm{T}_{1 / 2}$ & Kon \\
\hline & $n M$ & $\min ^{-1}$ & $\min$ & $n M^{-1} \mathrm{~min}^{-1}$ \\
Naldemedine & $0.51 \pm 0.03$ & 0.023 & 30.78 & 0.045 \\
Naloxone & $0.73 \pm 0.02$ & 0.290 & 2.44 & 0.397 \\
Naloxegol & $7.33 \pm 1.00$ & 0.390 & 1.78 & 0.053 \\
\hline
\end{tabular}




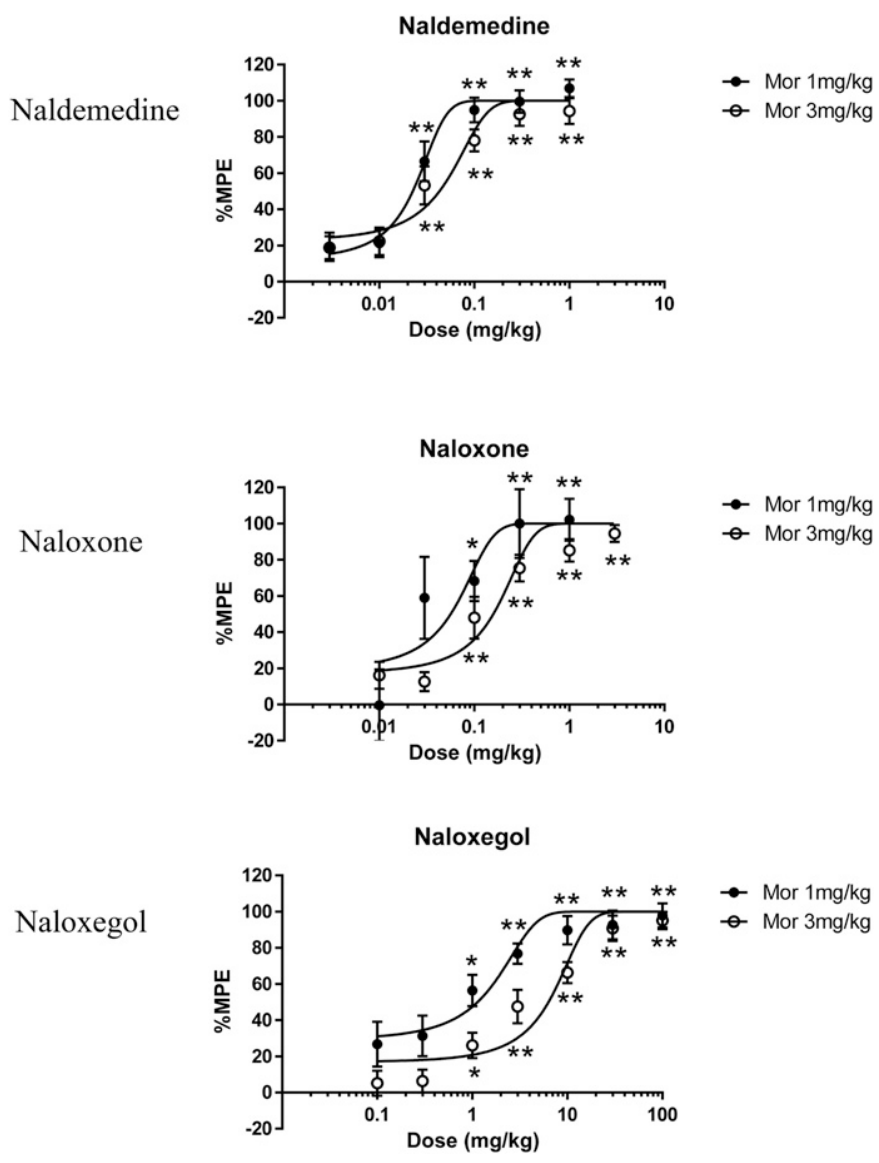

Fig. 3. Anti-small transit inhibitory effects at high and low morphine doses in rats. Effect on morphine-induced inhibition of small intestine transit in rats. Each point is the mean \pm S.E. of $7-10$ rats per group. ${ }^{*} P<0.05 ;{ }^{* *} P<0.01$ compared with vehicle control. Mor, morphine; MPE, maximal possible effect.

$18.5 \%$; and $\geq 400 \mathrm{MME}, 37.1 \%$. Therefore, there is no attenuation of the proportion of SBM responders with increasing opioid dose.

In the binding kinetics study, naldemedine showed slower association and dissociation kinetics compared with naloxone and naloxegol. Noncompetitive/insurmountable antagonism has been observed for many of the marketed small-molecule G-protein-coupled receptor antagonists, including the angiotensin-2 receptor-1 antagonists, the muscarinic M3 receptor antagonists, and the histamine $\mathrm{H} 1$ receptor antagonists. The insurmountable antagonism of these drugs is associated with very slow dissociation of the antagonist from the receptor (Swinney, 2004). In the nonpeptide corticotropinreleasing factor type-1 receptor antagonists, noncompetitive antagonist behavior appeared to be correlated to the corticotropin-releasing factor type-1 receptor off-rate kinetics (Ramsey et al., 2011). The slow dissociation kinetics profile of naldemedine might be associated with noncompetitive antagonism. Although the three compounds each have a morphinan scaffold, only naldemedine exhibited slow binding kinetics. The cause of the difference in binding kinetics requires further investigation, such as co-crystal structure analysis.

Regarding withdrawal symptoms in morphine-dependent rats, naldemedine showed a wider margin between the $\mathrm{ED}_{50}$ values of morphine-induced SIT inhibition and lowest severity of central withdrawal symptom compared with naloxone and
A
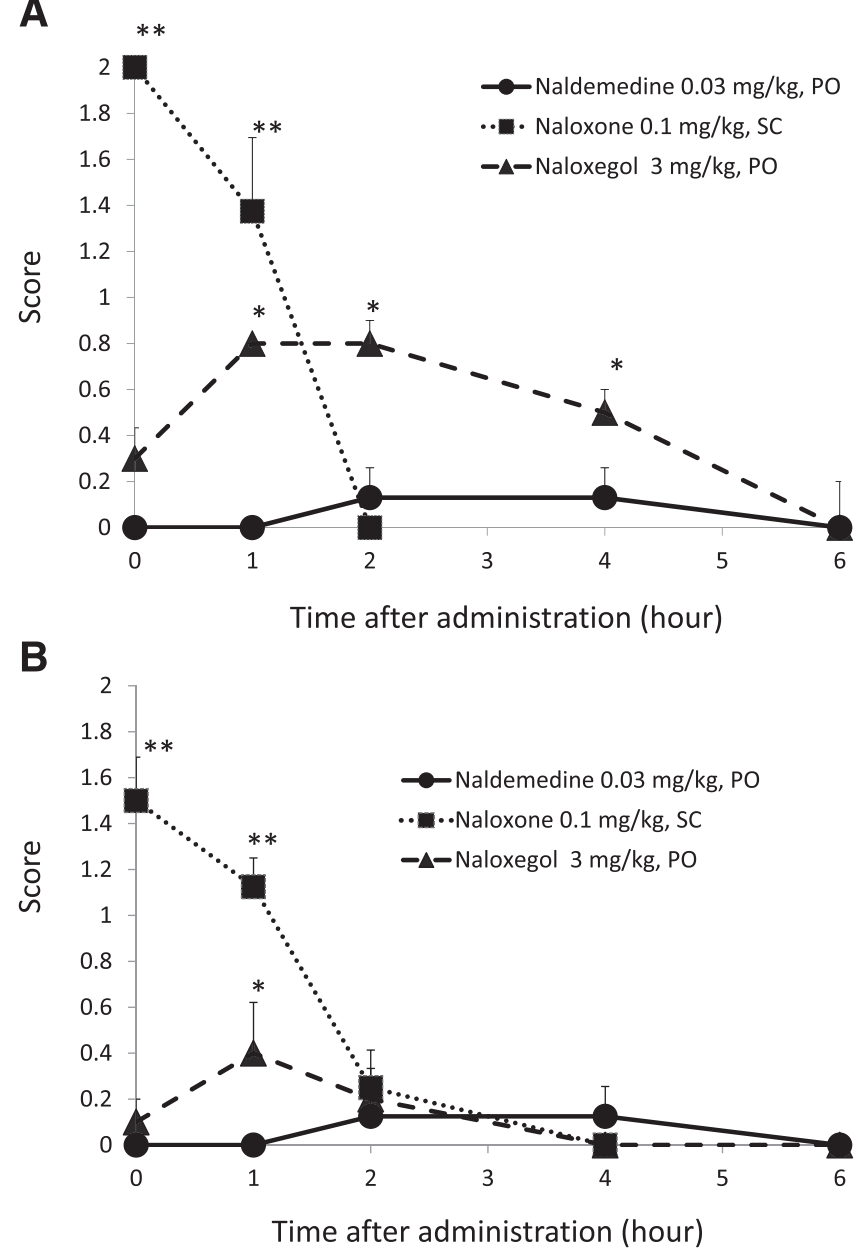

Fig. 4. (A) Precipitated peripheral withdrawal symptoms (diarrhea) of naldemedine, naloxone, and naloxegol in morphine-dependent rats. Data are mean \pm S.E. of $8-10$ rats per group. Statistical significance was determined using Steel's multiple comparison test (naldemedine) or Wilcoxon rank-sum test (naloxone and naloxegol) with respect to the corresponding vehicle control $(* P<0.05 ; * * P<0.01)$. (B) Precipitated central withdrawal symptoms (teeth chattering) of naldemedine, naloxone, and naloxegol in morphine-dependent rats. Data are mean \pm S.E. of 8-10 rats per group. Statistical significance was determined using Steel's multiple comparison test (naldemedine) or Wilcoxon rank-sum test (naloxone and naloxegol) with respect to the corresponding vehicle control $(* P<0.05 ; * * P<0.01)$.

naloxegol. This might be because of the difference in the brainto-plasma concentration ratio (brain $\mathrm{Kp}$ ). The brain $\mathrm{Kp}$ value of naldemedine is low (0.0184) in mice (Watari et al., 2019). Although brain $\mathrm{Kp}$ values of naloxone and naloxegol have not been reported, the $\mathrm{ED}_{50}$ values for the anticonstipation activity (intravenous $10 \mathrm{mg} / \mathrm{kg}$ morphine-induced gastrointestinal transit inhibition in rats) of oral naloxone and naloxegol were 0.69 and $23.1 \mathrm{mg} / \mathrm{kg}$, whereas those for the antianalgesic activity (intravenous $10 \mathrm{mg} / \mathrm{kg}$ morphineinduced nociception in the hot-plate model in rats) were 1.14 and $55.4 \mathrm{mg} / \mathrm{kg}$, respectively (Floettmann et al., 2017). The margins between the $\mathrm{ED}_{50}$ values of the anticonstipation and antianalgesic effects were 1.65 and 2.40, respectively. In contrast, the $\mathrm{ED}_{50}$ values for the anticonstipation effect (subcutaneous $3 \mathrm{mg} / \mathrm{kg}$ morphine-induced SIT inhibition in rats) of oral naldemedine was $0.03 \mathrm{mg} / \mathrm{kg}$, whereas naldemedine did not affect the subcutaneous $6 \mathrm{mg} / \mathrm{kg}$ morphine-induced 
analgesic effect in a rat tail-flick test up to $7 \mathrm{mg} / \mathrm{kg}$. The highest dose of naldemedine without an antianalgesic effect was 233 -fold higher than the $\mathrm{ED}_{50}$ value of naldemedine in the SIT study (Kanemasa et al., 2019). These data suggest the brain $\mathrm{Kp}$ value of naldemedine to be lower than that of naloxone and naloxegol. In addition to the difference in central withdrawal symptoms, naldemedine (oral $0.03 \mathrm{mg} / \mathrm{kg}$ ) showed a lower incidence and slower onset of a peripheral withdrawal symptom (diarrhea) compared with naloxone (subcutaneous $0.1 \mathrm{mg} / \mathrm{kg}$ ) and naloxegol (oral $3 \mathrm{mg} / \mathrm{kg}$ ) at a dose close to the $\mathrm{ED}_{50}$ value in the SIT study (Fig. 4). Administration of opioid antagonist while receptors are still occupied by an agonist displaces opioids from their receptors and results in the sudden onset of withdrawal (Sigmon et al., 2012). To alleviate a withdrawal symptom, a "soft landing" while allowing underlying neuroadaptations to revert gradually to their normal state is important, except for in emergency case, such as rapid withdrawal in the opioid-overdose situation. This suggests that the displacement rate of opioid agonist by opioid antagonist from $\mu$-opioid receptor contributes to the severity of withdrawal symptoms. Because naldemedine showed a slower association rate compared with naloxone and naloxegol, the rate of displacement by naldemedine might be slower than that by naloxone and naloxegol. As a result, naldemedine might show slower onset and milder peripheral withdrawal symptoms.

In an in vitro functional assay (Table 1), naldemedine, naloxone, and naloxegol showed similar antagonist activities to human $\mu$-opioid receptor. However, naldemedine showed more potent antagonist activity to human $\delta$ - and $\kappa$-opioid receptors than naloxone and naloxegol. Methylnaltrexone, another clinically available PAMORA, also showed human $\mu$-opioid receptorselective antagonist activity (Kanemasa et al., 2019). The $\delta$ - and $\kappa$-opioid receptor antagonist activities of naldemedine might not contribute to improvement of opioid-induced gastrointestinal transit inhibition because the morphine-induced inhibition on small and large intestinal transit was blocked by a $\mu$-opioid receptor-selective antagonist but not by $\delta$ - and $\kappa$-opioid receptor-selective antagonists (Matsumoto et al., 2016). However, $\delta$-opioid receptor antagonist activity contributes to improvement of opioid-induced nausea and vomiting, which are major adverse effects of opioids, because the $\delta$-opioid receptorselective antagonist, TAN-452, attenuated morphine-induced nausea and vomiting in ferrets (Suzuki et al., 2018). Therefore, naldemedine might influence opioid-induced nausea and vomiting via the $\delta$-opioid receptor.

In conclusion, we showed that naldemedine, naloxone, and naloxegol exert unique pharmacological effects because of their different modes of antagonism and binding kinetics. Although the pharmacological effects in the present study are not directly representative of the clinical pharmacological effects, our results provide important information for the clinical use of PAMORAs to manage the adverse effects of opioids.

\section{Acknowledgments}

All authors had complete access to the data that support this publication. We thank Dr. T. Suzuki (Hoshi University School of Pharmacy and Pharmaceutical Sciences, Tokyo, Japan) for helpful discussions.

\section{Authorship Contributions}

Participated in research design: Kanemasa, Nakamura, Morioka, Hasegawa.

Conducted experiments: Koike, Takase, Arai.

Performed data analysis: Koike, Takase, Arai.

Wrote or contributed to the writing of the manuscript: Kanemasa.

\section{References}

Bell T, Annunziata K, and Leslie JB (2009) Opioid-induced constipation negatively impacts pain management, productivity, and health-related quality of life: findings from the National Health and Wellness Survey. J Opioid Manag 5:137-144.

Benyamin R, Trescot AM, Datta S, Buenaventura R, Adlaka R, Sehgal N, Glaser SE, and Vallejo R (2008) Opioid complications and side effects. Pain Physician 11(2 Suppl):S105-S120.

Bruner HC, Atayee RS, Edmonds KP, and Buckholz GT (2015) Clinical utility of naloxegol in the treatment of opioid-induced constipation. J Pain Res 8:289-294.

Crockett SD, Greer KB, Heidelbaugh JJ, Falck-Ytter Y, Hanson BJ, and Sultan S; American Gastroenterological Association Institute Clinical Guidelines Committee (2019) American gastroenterological association institute guideline on the medical management of opioid-induced constipation. Gastroenterology 156:218-226.

Floettmann E, Bui K, Sostek M, Payza K, and Eldon M (2017) Pharmacologic profile of Naloxegol, a peripherally acting $\mu$-opioid receptor antagonist, for the treatment of opioid-induced constipation. J Pharmacol Exp Ther 361:280-291.

Hale M and Ko M (2019) Efficacy and safety of Naldemedine for opioid-induced constipation in patients with chronic non-cancer pain: subgroup analyses by opioid dose, \#77 in Pain Week; 2019 September

Hale M, Wild J, Reddy J, Yamada T, and Arjona Ferreira JC (2017) Naldemedine versus placebo for opioid-induced constipation (COMPOSE-1 and COMPOSE-2): two multicentre, phase 3, double-blind, randomised, parallel-group trials. Lancet Gastroenterol Hepatol 2:555-564.

Inagaki M, Kume M, Tamura Y, Hara S, Goto Y, Haga N, Hasegawa T, Nakamura T, Koike K, and Oonishi S (2019) Discovery of naldemedine: A potent and orally available opioid receptor antagonist for treatment of opioid-induced adverse effects. Bioorg Med Chem Lett 29:73-77.

Janković SM, Milovanović DR, and Janković SV (1999) Schild's equation and the best estimate of pA2 value and dissociation constant of an antagonist. Croat Med J 40:67-70. Kanemasa T, Koike K, Arai T, Ono H, Horita N, Chiba H, Nakamura A, Morioka Y, Kihara T, and Hasegawa M (2019) Pharmacologic effects of naldemedine, a peripherally acting $\mu$-opioid receptor antagonist, in in vitro and in vivo models of opioid-induced constipation. Neurogastroenterol Motil. 31:e13563.

Katakami N, Harada T, Murata T, Shinozaki K, Tsutsumi M, Yokota T, Arai M, Tada Y, Narabayashi M, and Boku N (2017) Randomized phase III and extension studies of naldemedine in patients with opioid-induced constipation and cancer. $J$ Clin Oncol 35:3859-3866.

Matsumoto K, Umemoto H, Mori T, Akatsu R, Saito S, Tashima K, Shibasaki M, Kato S, Suzuki T, and Horie S (2016) Differences in the morphine-induced inhibition of small and large intestinal transit: involvement of central and peripheral $\mu$-opioid receptors in mice. Eur J Pharmacol 771:220-228.

Morlion BJ, Mueller-Lissner SA, Vellucci R, Leppert W, Coffin BC, Dickerson SL, and O'Brien T (2018) Oral prolonged-release oxycodone/naloxone for managing pain and opioid-induced constipation: a review of the evidence. Pain Pract 18:647-665.

Ramsey SJ, Attkins NJ, Fish R, and van der Graaf PH (2011) Quantitative pharmacological analysis of antagonist binding kinetics at CRF1 receptors in vitro and in vivo. Br J Pharmacol 164:992-1007.

Saito Y, Yokota T, Arai M, Tada Y, and Sumitani M (2018) Naldemedine in Japanese patients with opioid-induced constipation and chronic noncancer pain: open-label phase III studies. J Pain Res 12:127-138.

Sigmon SC, Bisaga A, Nunes EV, O'Connor PG, Kosten T, and Woody G (2012) Opioid detoxification and naltrexone induction strategies: recommendations for clinical practice. Am J Drug Alcohol Abuse 38:187-199.

Suzuki T, Sawada T, Kawai K, and Ishihara Y (2018) Pharmacological profile of TAN-452, a novel peripherally acting opioid receptor antagonist for the treatment of opioid-induced bowel syndromes. Life Sci 215:246-252.

Swegle JM and Logemann C (2006) Management of common opioid-induced adverse effects. Am Fam Physician 74:1347-1354.

Swinney DC (2004) Biochemical mechanisms of drug action: what does it take for success? Nat Rev Drug Discov 3:801-808.

Watari R, Matsuda A, Ohnishi S, and Hasegawa H (2019) Minimal contribution of P-gp on the low brain distribution of naldemedine, a peripherally acting $\mu$-opioid receptor antagonist. Drug Metab Pharmacokinet 34:126-133.

Webster LR, Nalamachu S, Morlion B, Reddy J, Baba Y, Yamada T, and Arjona Ferreira JC (2018) Long-term use of naldemedine in the treatment of opioidinduced constipation in patients with chronic noncancer pain: a randomized, double-blind, placebo-controlled phase 3 study. Pain 159:987-994.

Address correspondence to: Dr. Toshiyuki Kanemasa, Neuroscience, Drug Discovery \& Disease Research Laboratory, Shionogi \& Co., Ltd., Shionogi Pharmaceutical Research Center, 3-1-1, Futaba-choToyonaka-shi, Osaka 5610825, Japan. E-mail: toshiyuki.kanemasa@shionogi.co.jp 